Document downloaded from:

http://hdl.handle.net/10251/43294

This paper must be cited as:

Cabrera Rochera, E.; Cobacho Jordán, R.; Estruch Guitart, V.; Aznar Bellver, J. (2011). Analytical hierarchical process (AHP) as a decision support tool in water resources management. Aqua. 60.6:343-351.

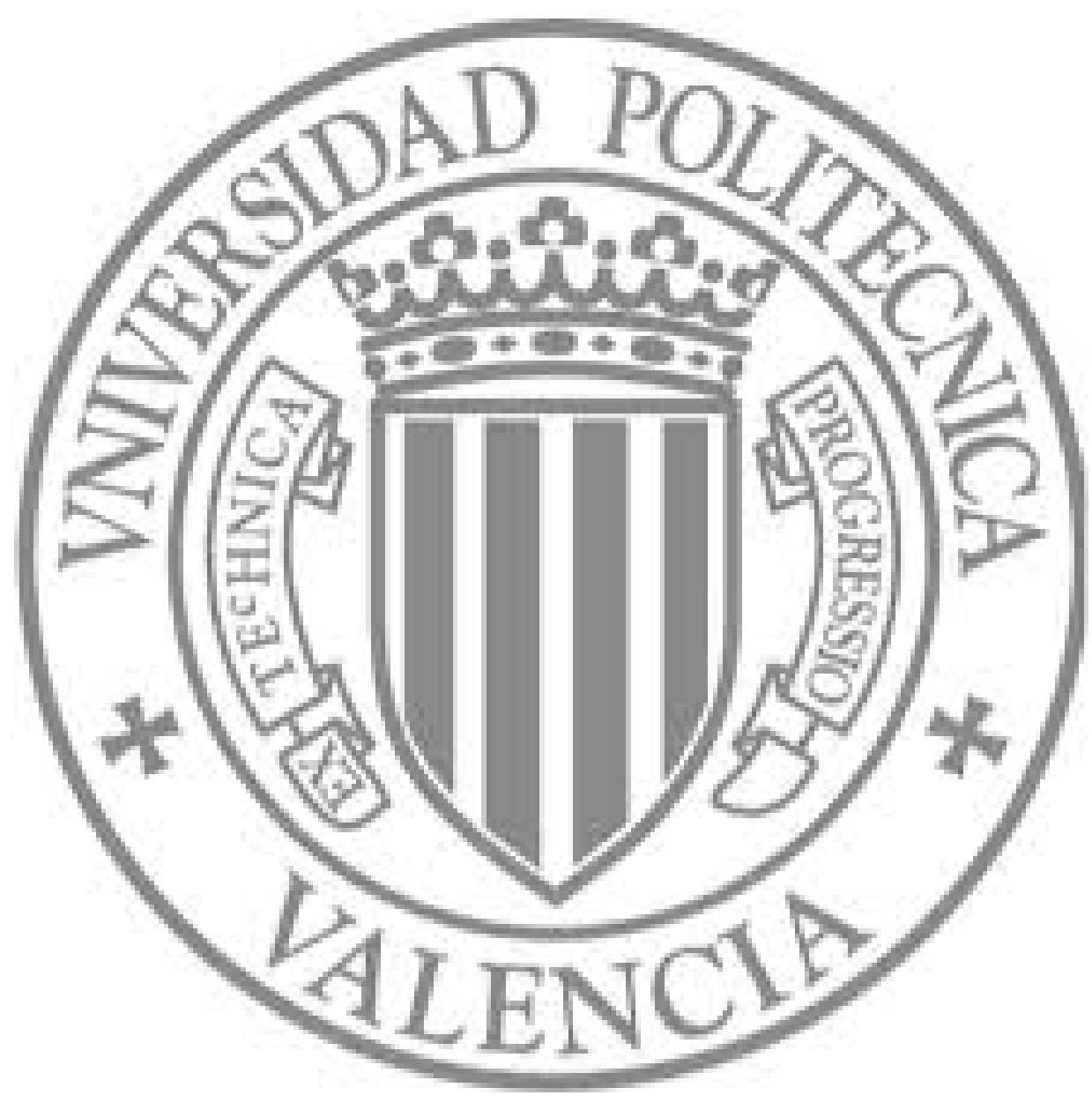

The final publication is available at

http://dx.doi.org/10.2166/aqua.2011.016

Copyright IWA Publishing 


\title{
Analytical hierarchical process (AHP) as a decision support tool in water resources management
}

Enrique Cabrera Jr, Ricardo Cobacho, Jerónimo Aznar and Vicent Estruch

Enrique Cabrera Jr, Ricardo Cobacho

ITA - Dpto. Ingeniería Hidráulica y Medio Ambiente, Universitat Politècnica de València. Camino de Vera s/n. 46022.Valencia, Spain

Jerónimo Aznar, Vicent Estruch

Dpto Economia y Ciencias Sociales, Universitat Politècnica de València. Camino de Vera s/n. 46022. Valencia, Spain

e-mail: qcabrera@ita.upv.es

Short title: AHP as a decision support tool in water resources management

\begin{abstract}
Despite advances in water conservation, abstraction and transport, water demand has been increasing worldwide in the past few decades. This has resulted in an increased pressure on stakeholders to provide sustainable solutions to meet future water demands. The decision-making process to find those solutions is becoming increasingly complicated. First, owing to the arrival of new technologies or the evolution of existing ones, the number of available alternatives has increased. Additionally, economic criteria have been abandoned as the sole reference for the comparison of alternatives. The increase of both options and restrictions has complicated significantly the choice of the best alternative. Until now, the search for solutions has usually focused on the reduction of all parameters and restrictions to a common denominator or the use of complex and scarcely transparent models. This paper shows how to make use of the AHP technique to improve the decision-making process in order to satisfy new water demands in a local context. This methodology has been widely used in other fields and allows the combination of quantitative and qualitative criteria. Among the virtues of AHP are transparency, simplicity and the fact that it relies on actual opinions from experts.
\end{abstract}

Key words | decision-making process, water management, water policy, water resources management

\section{PROBLEM DESCRIPTION}


Satisfying growing water demands is a problem as old as civilization itself. Yet despite the problem remaining the same for centuries, the available solutions have certainly evolved, and even increased in number, in the past decades. Technical difficulties are becoming a lesser concern with the ever-evolving engineering techniques; however, restrictions on the possible solutions are now much greater as a result of greater environmental concerns and social pressure. And so, alternatives to the traditional civil engineering options such as desalination or water reuse are now available. In other words, the traditional economic criteria have now been joined by additional social and environmental restrictions.

Nowadays, the decision-making process ending in the selection of a certain project is complex and needs to take into account a triple bottom line approach (Elkington 1994). In other words, the environmental impact, the social consequences and, inevitably, the economic cost of the solution are to be weighed. In practice, this implies a simultaneous analysis of factors of a very different nature that are assessed in non-comparable units. Decision-making is greatly affected by this fact, for it is extremely complicated to assess economic, and therefore quantitative, factors in conjunction with social or environmental factors that are often of a qualitative nature.

\section{THE TRADITIONAL ECONOMIC APPROACH}

A quick revision of the traditional methodology used to decide between different supply alternatives inevitably leads to the dominating approach: the increase of available water volume subject to the economic viability of the investment.

In the past, when management from the supply side was the only alternative considered by decision makers, all alternatives were in fact civil works aimed to increase the amount of available water. Under those circumstances, the decision was often made attending to the value of economic indicators (for instance the net present value, NPV, or the internal return rate, IRR). By using such ratios, it was possible to prioritize the most cost-effective option for the life span of the infrastructure.

By the late 1980s, demand management appeared in the toolbox of water resources planners, complicating the decision-making process slightly. By choosing a demand management alternative, there was no increase of the available volume but rather a decrease in the amount of water needed to satisfy the users' needs. The traditional method was adapted to face these new circumstances, and a simple change in perspective was enough. After all, every cubic metre that was saved was in fact an additional cubic metre available for consumption. Therefore, the use of the NPV for the selection of alternatives (both from the 
demand and offers sides) was tackled as a cost-benefit analysis and a cost-effectiveness analysis (Pekelney et al. 1996; SPU 1998).

Demand management has progressed as a real alternative over the past two decades. However, looking back at the last edition of what could possibly be the most relevant congress on the topic (the Efficient conference series, from the International Water Association), the use of economic parameters such as the NPV and the unit costs of every cubic metre, are still the basis for the decision support methods presented (Fane \& Turner 2009).

The reasons behind this overwhelming presence of economic criteria are easy to understand. One of them is the obvious inertia that any methodology presents after many years as the leading alternative. Another one is the fact that the budget is one of the greatest restrictions any project has to face. Additionally, any stakeholder can immediately relate to monetary quantities, and the world is witnessing an increasing trend of monetizing almost anything. As a result of all of the above, currency is presented as the desired common denominator that allows setting comparisons and, finally, making decisions.

However, despite the belief that anything can be turned into dollars or euros, the fact is that the restrictions which need to be faced nowadays in water management decisions are more variable, complex and relevant than they ever were.

As a matter of fact, the problem that needs to be solved (quite simply the need for more water) can now be solved in many additional ways. Efficiency measures and programmes are becoming more creative, cost effective and technically advanced. In parallel, triple bottom line criteria have improved the profile of those solutions in which less is more. However, this kind of analysis greatly increases the difficulty of the decision-making process, introducing qualitative and intangible variables in the mix.

In summary, the problem to solve may be the same one that troubled most civilizations in human history: satisfying human water needs. However, we now know many more ways to solve it, and we are also concerned about things that never troubled our predecessors. If the omnipresent costs are added to the equation, decision makers are faced with a challenge that can no longer be faced with a simple tool such as converting all factors into money. A new methodology, which can accommodate qualitative aspects while keeping the important influence of economic factors, is needed; a method that is transparent enough to provide traceability to the results and at the same time avoid biased decisions. 
The authors believe that the analytic hierarchy process (AHP) fulfils all the requirements and represents an improved solution to this decision-making problem.

\section{THE ANALYTIC HIERARCHY PROCESS (AHP)}

The analytic hierarchy process is a method that provides a choice between different alternatives (strategies, investments, etc.) based on a series of criteria or variables, which are usually in conflict (Saaty 1980).

The method consists of the following steps:

a) The starting points are the different possible alternatives that a decision maker faces: A1, A2, A3, shown in Figure 1.

b) The criteria used to make the selection are then specified. In other words, those characteristics that may turn one of the alternatives into a more desirable one than its peers.

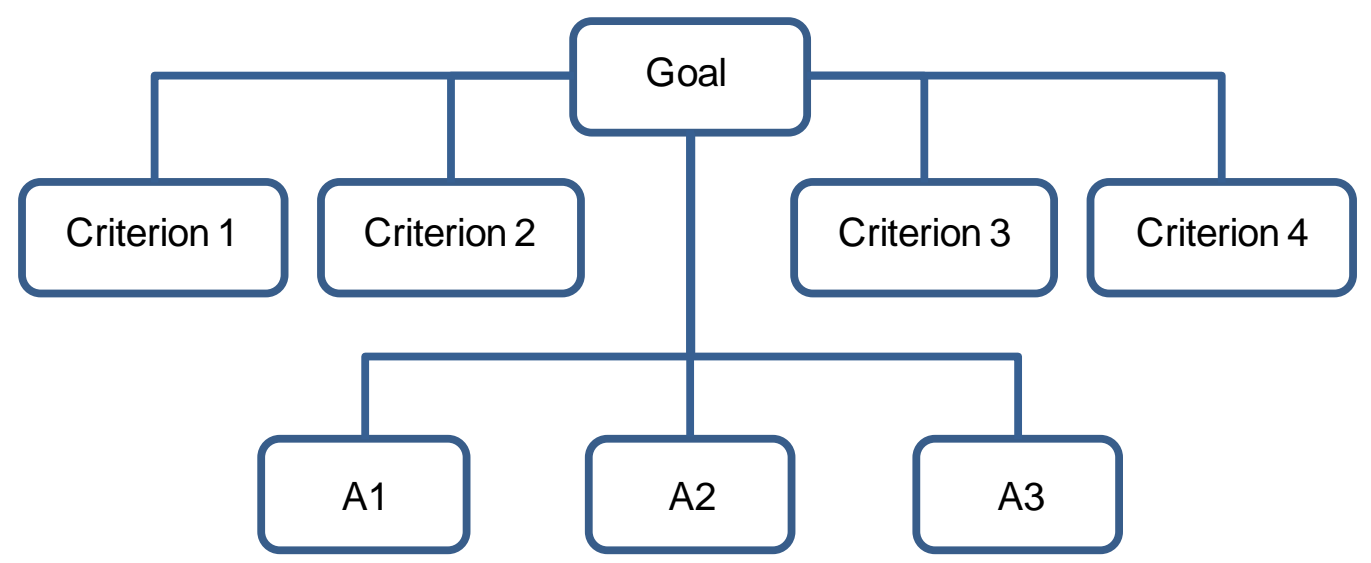

Figure 1 | Graphical representation of a hierarchy

c) Once the alternatives are known and the criteria have been defined, the relative importance of each criterion is determined and weighed. This is one of the contributions from the method and is achieved by a comparison by pairs and a fundamental scale proposed by Saaty (Table 1). A matrix is then built by means of those comparisons, and its eigenvector shows the weight or importance of each one of the criteria.

d) Taking into account the criteria and their weights, the different alternatives are assessed obtaining $n$ matrices, as many as the criteria. From each one of them, the eigenvector is calculated which will show the weight of the alternative as a function of each criterion. 
e) From the two previous processes ( $\mathrm{c}$ and d) two additional matrices are obtained. A column matrix $\mathrm{nx} 1$ with the weights for the criteria (for $n$ criteria) and another matrix mxn formed by the weights of the different alternatives taking into account all the criteria and their importance.

f) The product of both matrices will produce a matrix $m x 1$ that will prioritize the different alternatives taking into account all the criteria and their importance.

The method may seem, described with words, quite confusing. However, its application is very simple. It could also be argued that the weighing of the different criteria and prioritization of alternatives could be done directly without the proposed methodology. In other words, a decision maker could determine the importance of every alternative (for instance from 1 to 10). However, the simultaneous consideration of a large number of alternatives becomes quite a complex problem to solve (Miller 1956; Arrow \& Raynaud 1986).

Saaty proposed paired comparisons as a tool to overcome this limitation in the capacity of processing options. The human brain is adapted to the comparison of two alternative choices. This is the origin of his fundamental scale of absolute numbers (Table 1).

\begin{tabular}{lll}
$\begin{array}{l}\text { Intensity of } \\
\text { importance }\end{array}$ & Definition & Explanation \\
\hline 1 & $\begin{array}{l}\text { Equal importance } \\
\text { Moderate importance }\end{array}$ & $\begin{array}{l}\text { Two activities contribute equally to the objective } \\
\text { Experience and judgement slightly favour one activity } \\
\text { over another } \\
\text { Experience and judgement strongly favour one activity } \\
\text { over another } \\
\text { An activity is favoured very strongly over another; its } \\
\text { dominance demonstrated in practice }\end{array}$ \\
& Strong importance & $\begin{array}{l}\text { The evidence favouring one activity over another is of } \\
\text { the highest possible order of affirmation }\end{array}$ \\
\hline
\end{tabular}

Table 1 | Fundamental scale of absolute numbers (Saaty 1980)

Taking into account the scale in Table 1, the square matrices (nxn) described previously are built. These matrices fulfil conditions of reciprocity, homogeneity and consistency. In all cases, once the paired comparisons matrix is built, its consistency needs to be checked. This is one of the method's strengths, as it enables us to make sure that the information introduced in the model is correct (or at least consistent). The consistency ratio (CR) is the tool used for this purpose. The CR needs to be smaller than certain preset percentages that are a function of the matrix range (range $3, \mathrm{CR}<5 \%$; range $4 \mathrm{CR}<9 \%$; range 5 or higher, $\mathrm{CR}<10 \%$ ).

Once the consistencies of the matrices are verified, their eigenvectors are calculated. The eigenvector corresponding to the criteria matrix, $V \mathrm{c}$, shows the relative importance of each of the criteria 
for the assessment of all the alternatives which are being considered. The eigenvector from the alternatives matrix for a certain criterion, Vai (column vector), shows the weight or relative importance of each one of the alternatives for criterion $i$. The number of eigenvectors obtained (Va1, Va2,.. Van) matches the number of criteria $(n)$, and the number of elements of each vector is equal to the number of alternatives $(m)$.

During the last step of the process (f) the eigenvectors alternative matrix is multiplied by criteria ranking matrix:

$V_{a} * V_{c}=w$

Being:

$V_{a}=\left(V_{a 1}, V_{a 2}, \cdots, V_{a m}\right), \operatorname{dim}\left(V_{a}=m * n\right)$

The result is a matrix $w$ showing the relative importance of each alternative. This figure is the one that allows the ranking of all alternatives from least to most desirable, and quantifies the interest of each alternative with respect to the others as a function of all criteria and their importance, therefore allowing us to choose the best.

\section{EXAMPLE}

In order to illustrate the method, an example is presented with the case of a synthetic Mediterranean city of 1.5 million inhabitants (Figure 2). The volume of water injected in the system is $360,000 \mathrm{~m}^{3} / \mathrm{day}$, corresponding to a rate per capita of 240 1/person/day. The consumed volume is $270,000 \mathrm{~m}^{3} /$ day (180 1/person/day) and losses in the distribution system total $90,000 \mathrm{~m}^{3} /$ day (which is $25 \%$ of the injected volume).

The managers of the water supply to the city are developing a long-term master plan and have identified the next difficult points to consider:

- In about 15 to 20 years from now, the population of the city is expected to increase by another 100,000 inhabitants $(6.7 \%$ of the current population).

- The capacity of the water supply system $\left(360,000 \mathrm{~m}^{3} /\right.$ day $)$ is being fully used at the moment.

- Water resources in the area have been decreasing in recent years, probably because of climate change. To avoid unexpected shortages, a conservative approach to the problem is needed, so the 
future scenario to solve is the following: the city would need to supply adequate water for the total foreseen population only in 5 years time, and even so, an extra capacity reserve of $30,000 \mathrm{~m}^{3} /$ day would have to be readably available.

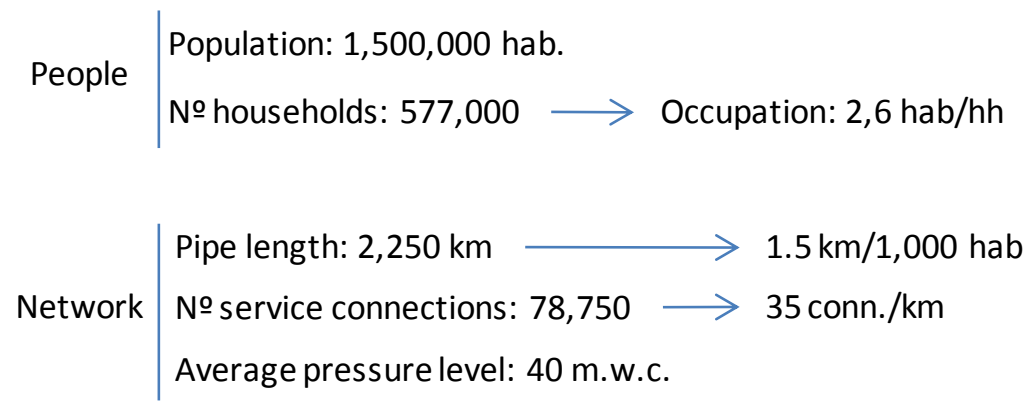

Figure 2 | Basic data for the example city

Finally, four different alternative actions have been identified (Figure 3 and Table 2), and each one of them has been properly sized to solve (reliably enough) the future scenario described above:

1. Desalination plant: The construction of a plant would increase available daily resources by the necessary volume. This kind of solution offers reassurance to decision makers as it guarantees the availability of the resource. Additionally, the construction of a new plant is visible to tax payers and a marketable asset from a political perspective. However, a desalination plant may not work at full capacity for many years with all the technical and economic disadvantages associated with this situation. Additionally, the environmental impact is high, especially taking into account the carbon footprint of an energy-intensive process and the possible impact on the surrounding marine area. 
2. Final uses reduction: A programme to achieve the reduction of demand, applied to the current and future population (every 10 years) would achieve estimated savings of $18.5 \%$. This programme would include retrofitting, rebates and raising user awareness by means of professional training, education in schools and media campaigns. This kind of solution has only one downside which is a slight uncertainty in the results. The target savings are considered feasible and are neither on the optimistic or pessimistic sides. However the advantages are many, with positive environmental impact (less consumption means less pollution) and good levels of acceptance and response from the users.

3. Pipe renewal: The renovation of $50 \%$ of the network every 25 years is another alternative which would reduce leakage levels by $8 \%$ thus achieving the necessary savings to satisfy future needs. This is also an environmentally sound option, although not as clear as option 2 . On the other hand, the users' perception of this kind of action is not very good. Disruptions caused by works and the lack of visible improvements (all changes remain underground and the service apparently is the same) are the reasons behind this perception.

4. Reallocation of irrigation water: Given the agricultural nature of the area, a final option to obtain the extra volume is to incentivize local farmers to release the necessary daily water. In order to achieve this reduction, the proposal is to convert the current maize production (needing $8,000 \mathrm{~m}^{3} / \mathrm{ha}$ ) into barley. An analysis of costs and revenues (Moreno 2008) allows an estimate of the compensation needed for the farmers of $€ 1,739,000 /$ year.

Once the different alternative solutions to the problem have been defined, it is necessary to select the most adequate one. Typically, the selection will be based on choosing the most sustainable alternative, in the broad sense of the term. Sustainability is a widely used concept but, despite its popularity since its inclusion in the Brundtland Report (WCED 1987), it is still a vague one and empirically difficult to achieve. In our case, a triple bottom line approach is suggested, considering the economic, social and environmental sustainability. 


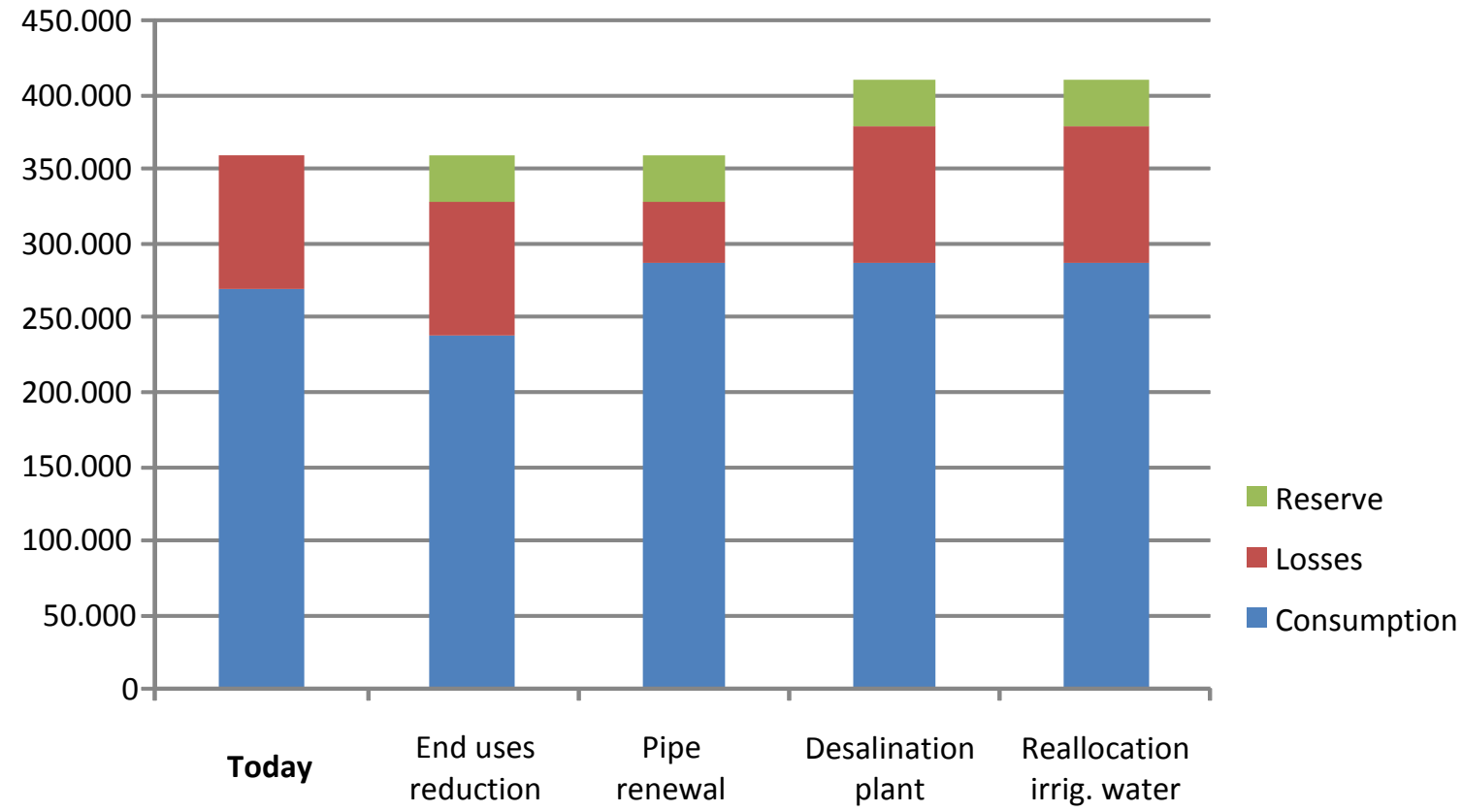

Figure 3 | Comparison of four possible alternatives

\begin{tabular}{|c|c|c|c|c|c|}
\hline & Today & $\begin{array}{l}\text { End uses } \\
\text { reduction }\end{array}$ & $\begin{array}{l}\text { Pipe } \\
\text { renewal }\end{array}$ & $\begin{array}{l}\text { Desalination } \\
\text { plant }\end{array}$ & $\begin{array}{l}\text { Reallocation } \\
\text { irrig. water }\end{array}$ \\
\hline Investment costs & - & $\begin{array}{l}53.6 € \\
\text { millions/10 } \\
\text { years }\end{array}$ & $\begin{array}{l}226.4 € \\
\text { millions/25 } \\
\text { years }\end{array}$ & $\begin{array}{l}48.8 \\
€ \text { milions/50 } \\
\text { years }\end{array}$ & - \\
\hline Operation costs & - & - & - & $\begin{array}{l}€ 6.7 \\
\text { million/year }\end{array}$ & $\begin{array}{l}€ 1.7 \\
\text { million/year }\end{array}$ \\
\hline Increment in capacity $\left(\mathrm{m}^{3} / \mathrm{d}\right)$ & - & - & - & 50,000 & 50,000 \\
\hline Reduction in use $\left(\mathrm{m}^{3} / \mathrm{d}\right)$ & - & 30,802 & 31,910 & - & - \\
\hline Total capacity $\left(\mathrm{m}^{3} / \mathrm{d}\right)$ & 360,000 & 360,000 & 360,000 & 410,000 & 410,000 \\
\hline Network input $\left(\mathrm{m}^{3} / \mathrm{d}\right)$ & 360,000 & 329,198 & 328,090 & 378,814 & 378,814 \\
\hline Consumption $\left(\mathrm{m}^{3} / \mathrm{d}\right)$ & 270,000 & 238,475 & 288,090 & 288,090 & 288,090 \\
\hline Losses $\left(\mathrm{m}^{3} / \mathrm{d}\right)$ & 90,000 & 90,724 & 40,000 & 90,724 & 90,724 \\
\hline Reserve $\left(\mathrm{m}^{3} / \mathrm{d}\right)$ & - & 30,802 & 31,910 & 31,186 & 31,186 \\
\hline
\end{tabular}

Table 2 | Main figures for each alternative

As a consequence, the following criteria have been considered:

- Economic: The direct costs of each option, discriminating between investment and operating costs.

- Social: These criteria take into account the different perspectives from which society will assess each alternative. Three of these perspectives have been considered: 
- Social alarm: the potential rejection degree that each alternative may produce in the population.

○ Impact on the job market: how many jobs each option may create locally. Impact on the water price: quantifying the percentage of increase or reduction in the average water bill that each alternative will produce.

- Environmental: The last group of criteria takes into account the effects that each of the alternatives would have on the environment:

- Conservation of water masses: how each alternative would affect the water resources of the region, including potential impact on the sea water of the desalination plant.

- Wastewater discharge: assesses the influence (and possible change) on the urban wastewater volumes generated considering each alternative.

- Carbon emissions: quantifies directly the contribution to greenhouse gas emissions resulting from implementing each option.

Some of these criteria are, undoubtedly, of a different nature. More specifically, they can be classified as follows:

- Criteria assessed as benefits (impact on the job market and the conservation of water masses) vs. criteria assessed as costs (investment and operating costs).

- Quantitative criteria (QNT, those that are easily represented by a figure: for instance all costs) vs. qualitative criteria (QLT, those that are often intangible and difficult to assess numerically). The treatment of both types is different. The weights of the quantitative criteria are obtained normalizing the sum of the respective quantities, while for the qualitative measures the weights derive from the eigenvector of the comparison matrices.

Figures 4 and 5 show the hierarchies of benefits and costs respectively. 


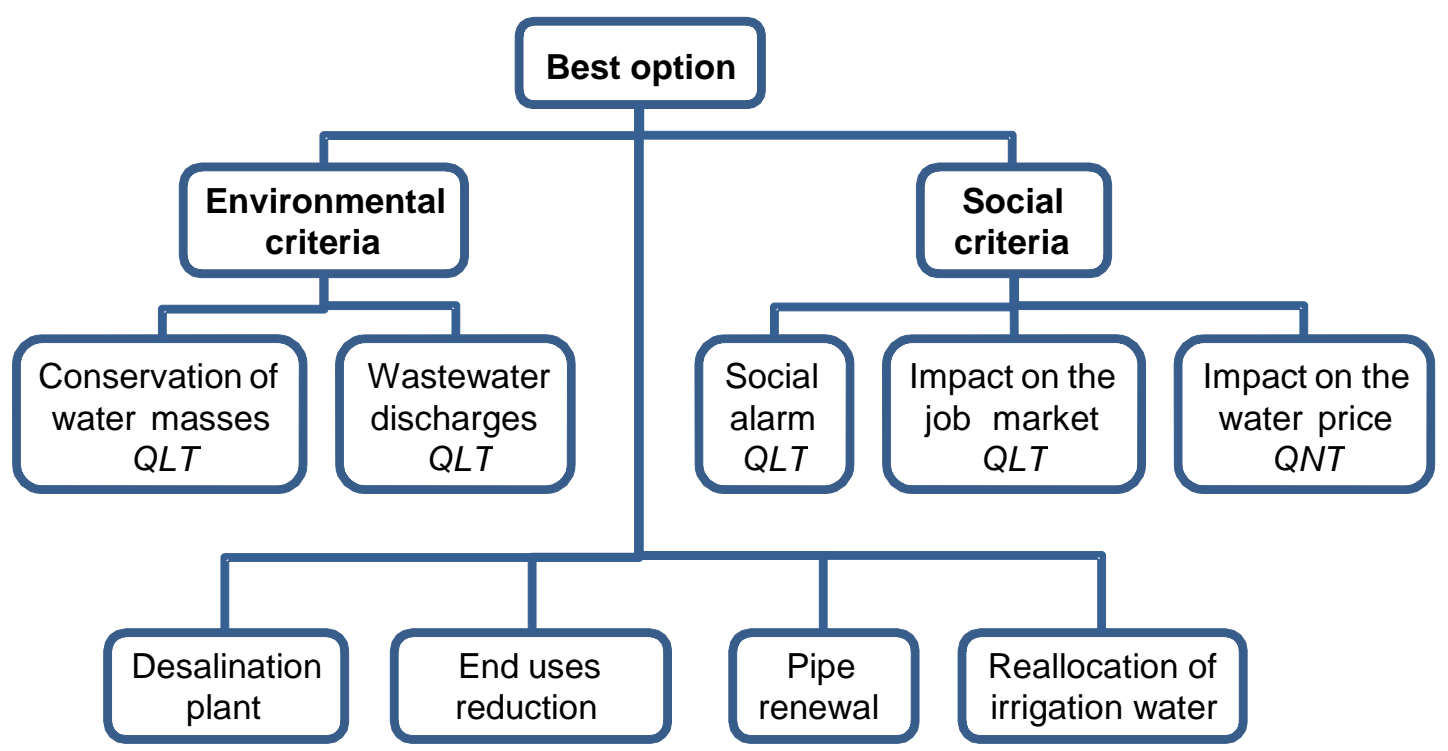

Figure 4 | Benefits hierarchy

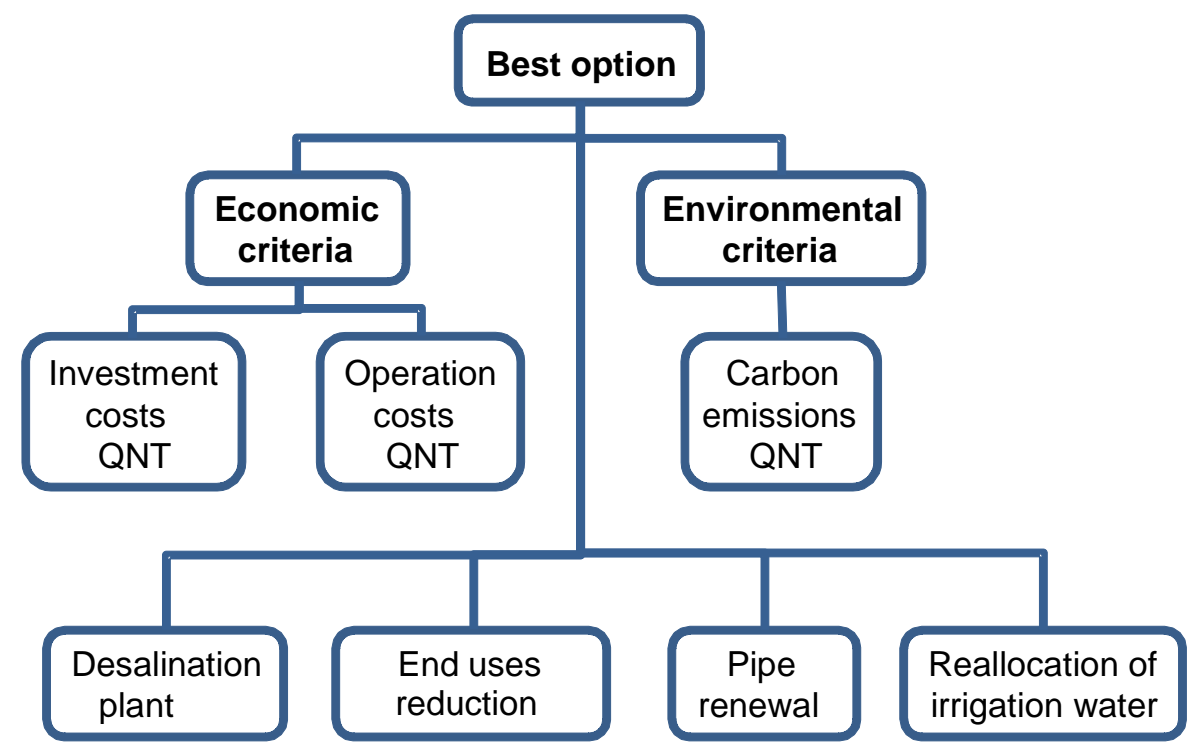

Figure 5 | Costs hierarchy

In order to select the best option from the available alternatives, six experts in water management were questioned. Their opinions were surveyed by means of paired comparisons that were used applying the method described above. More specifically, the experts provided successively:

1. The direct comparison of criteria, within each hierarchic level and for both costs and benefits.

2. In the benefits hierarchy, the comparison of all four alternatives with respect to each of the second level criteria. 
3. In the costs hierarchy, all alternatives were prioritized with respect to each criterion by normalizing the sum of the respective sums, since all second level criteria were quantitative.

Table 3 shows the weights assigned to the benefits criteria, while Table 4 shows the weight of each alternative with respect to each one of those criteria.

\begin{tabular}{|c|c|c|c|c|c|}
\hline \multirow{6}{*}{ Benefits } & Criteria level & $1^{\text {st }}$ Hierarchy & Criteria & $2^{\text {nd }}$ Hierarchy & Prioritization \\
\hline & \multirow{2}{*}{ Environmental } & \multirow{2}{*}{0.5815} & Conservation of water masses & 0.5807 & 0.3377 \\
\hline & & & Wastewater discharges & 0.4193 & 0.2438 \\
\hline & \multirow{3}{*}{ Social } & \multirow{3}{*}{0.4185} & Social alarm & 0.2045 & 0.0856 \\
\hline & & & Impact on the job market & 0.3664 & 0.1533 \\
\hline & & & Impact on the water price & 0.4289 & 0.1795 \\
\hline
\end{tabular}

Table 3 | Weights of the benefits criteria

\begin{tabular}{lccccc} 
Alternatives & Conservation of & \multicolumn{3}{c}{ Benefits criteria } \\
& water masses & $\begin{array}{c}\text { Wastewater } \\
\text { discharges }\end{array}$ & $\begin{array}{c}\text { Social } \\
\text { alarm }\end{array}$ & $\begin{array}{c}\text { Impact on the } \\
\text { job market }\end{array}$ & $\begin{array}{c}\text { Impact on the } \\
\text { water price }\end{array}$ \\
\hline Desalination plant & 0.0503 & 0.0824 & 0.0666 & 0.3149 & 0.2878 \\
End uses reduction & 0.4275 & 0.5254 & 0.4610 & 0.2592 & 0.2121 \\
$\begin{array}{l}\text { Pipe renewal } \\
\text { Reallocation of }\end{array}$ & 0.4378 & 0.2863 & 0.3039 & 0.3011 & 0.0946 \\
irrigation water & 0.0844 & 0.1059 & 0.1685 & 0.1248 & 0.4055 \\
\hline
\end{tabular}

Table 4 | Prioritization of the alternatives with respect to each of the benefits criteria

Table 5 shows the product of the previous prioritizations and, as a result, the final priorities of alternatives taking into account all criteria and their relative importance.

Benefits criteria

\begin{tabular}{lccccccc} 
Alternatives & $\begin{array}{c}\text { Conservation of } \\
\text { water masses }\end{array}$ & $\begin{array}{c}\text { Wastewater } \\
\text { discharges }\end{array}$ & $\begin{array}{c}\text { Social } \\
\text { alarm }\end{array}$ & $\begin{array}{c}\text { Impact } \\
\text { on the } \\
\text { job } \\
\text { market }\end{array}$ & $\begin{array}{c}\text { Impact on } \\
\text { the water } \\
\text { price }\end{array}$ & $\begin{array}{c}\text { Criteria } \\
\text { prioritization }\end{array}$ & $\begin{array}{c}\text { Alternatives } \\
\text { prioritization }\end{array}$ \\
\hline Desalination plant & 0.0503 & 0.0824 & 0.0666 & 0.3149 & 0.2878 & 0.3377 & $\mathbf{0 . 1 4 2 7}$ \\
End uses reduction & 0.4275 & 0.5254 & 0.4610 & 0.2592 & 0.2121 & 0.2438 & $\mathbf{0 . 3 8 9 7}$ \\
$\begin{array}{l}\text { Pipe renewal } \\
\text { Reallocation of }\end{array}$ & 0.4378 & 0.2863 & 0.3039 & 0.3011 & 0.0946 & 0.0856 & $\mathbf{0 . 3 0 6 8}$ \\
irrigation water & 0.0844 & 0.1059 & 0.1685 & 0.1248 & 0.4055 & 0.1533 & $\mathbf{0 . 1 6 0 7}$ \\
\hline
\end{tabular}

0.1795

Table 5 | Final prioritization of the alternatives with respect to the benefits criteria

In parallel, and considering the costs criteria, Table 6 shows the weights of such criteria, while Table 7 displays the weights of each alternative with respect to them. Finally, Table 8 prioritizes each alternative as a function of all of them and their importance.

Costs Criteria level $\mathbf{1}^{\text {st }}$ Hierarchy Criteria $\quad 2^{\text {nd }}$ Hierarchy Prioritization




\begin{tabular}{lllll}
\hline Economic & 0.6859 & Investment costs & 0.2483 & 0.1703 \\
& & Operation costs & 0.7517 & 0.5156 \\
Environmental & 0.3140 & Carbon emissions & & 0.3140 \\
\hline
\end{tabular}

Table 6 | Weights of the cost criteria

\begin{tabular}{|c|c|c|c|}
\hline \multirow{2}{*}{ Alternatives } & \multicolumn{3}{|c|}{ Costs criteria } \\
\hline & Investment costs & Operation costs & Carbon emissions \\
\hline Desalination plant & 0.0691 & 0.7946 & 1.0000 \\
\hline End uses reduction & 0.3369 & 0.0000 & 0.0000 \\
\hline Pipe renewal & 0.5940 & 0.0000 & 0.0000 \\
\hline $\begin{array}{l}\text { Reallocation of } \\
\text { irrigation water }\end{array}$ & 0.0000 & 0.2054 & 0.0000 \\
\hline
\end{tabular}

Table 7 | Prioritization of each alternative with respect to costs criteria

\begin{tabular}{lccccc}
\multicolumn{1}{c}{ Alternatives } & Investment costs & $\begin{array}{c}\text { Costs criteria } \\
\text { Operation } \\
\text { costs }\end{array}$ & $\begin{array}{c}\text { Carbon emissions } \\
\text { Criteria }\end{array}$ & $\begin{array}{c}\text { Alternatives } \\
\text { prioritization }\end{array}$ \\
\hline Desalination plant & 0.0691 & 0.7946 & 1.0000 & 0.1703 & $\mathbf{0 . 7 3 5 4}$ \\
End uses reduction & 0.3369 & 0.0000 & 0.0000 & 0.5156 & $\mathbf{0 . 0 5 7 4}$ \\
Pipe renewal & 0.5940 & 0.0000 & 0.0000 & 0.3140 & $\mathbf{0 . 1 0 1 2}$ \\
$\begin{array}{l}\text { Reallocation of } \\
\text { irrigation water }\end{array}$ & 0.0000 & 0.2054 & 0.0000 & & $\mathbf{0 . 1 0 5 9}$ \\
\hline
\end{tabular}

Table 8 | Final weights for the alternatives with respect to the costs criteria

The cost/benefit ratio shown in Table 9 indicates the prioritization of the four alternatives considering simultaneously cost and benefit criteria and their importance. The conclusion is that the best alternative is the final uses reduction, followed by leakage management, the change in crops and finally the desalination plant.

\begin{tabular}{lccc}
\multicolumn{1}{c}{ Alternative } & Benefits & Costs & Ratio \\
\hline Desalination plant & 0.1427 & 0.7354 & $\mathbf{0 . 1 9}$ \\
End uses reduction & 0.3897 & 0.0574 & $\mathbf{6 . 7 9}$ \\
Pipe renewal & 0.3068 & 0.1012 & $\mathbf{3 . 0 3}$ \\
Reallocation of & 0.1607 & 0.1059 & $\mathbf{1 . 5 2}$ \\
irrigation water & & & \\
\hline
\end{tabular}

Table 9 | Cost/benefit ratio

\section{CONCLUSIONS}

The AHP method is a methodical approach to decision making. Despite the many matrices and the mathematical calculations, AHP is able to 'add' in a systematic and unbiased way the opinions of experts, quantitative measures and economic factors. This represents a significant advantage from a purely economic method that bases decisions solely on costs. 
It must be stressed that AHP does not colour the results in any way. In other words, the mathematical framework based on matrices does not introduce any bias and has no contribution to the final result. The ranking of choices is solely determined by the different inputs of the experts and the numerical data. Consequently the AHP methodology is only as good as those opinions and data, and this is of course one of the main limitations of the method.

However, when comparing AHP with how decisions are made nowadays in this kind of project, this disadvantage also becomes the main strong point for the methodology. Decision making is a human function, and it is based on empirical experience and rational thinking. AHP is a very useful tool to channel all that knowledge from as many experts as needed and organize it systematically, obtaining a clear and organized solution.

With the introduction of AHP into decision-making processes, it is possible to take qualitative factors into the equation. This is a key development as it is nowadays generally accepted that environmental and social factors (which are hard to measure) should be taken into account. However, previously presented methodologies failed to integrate them at the same level as economic factors.

This paper has presented a synthetic data example that shows how AHP can be used to determine the best alternative to secure new water resources. While the case is not completely real, it is fully applicable to real life, as only quantitative data and expert opinions would actually change. The methodology can easily accommodate additional options and restrictions, making its adaptation to other cases very simple.

\section{ACKNOWLEDGEMENTS}

The Ministry of Education and Science of Spain through Project No CGL2008-01910/BTE has supported this research.

\section{REFERENCES}

Arrow, K.J. \& Raynaud, H. 1986 Social Choice and Multicriteria Decision-Making. Massachusetts Institute of Technology, Cambridge, MA.

Elkington, J. 1994 Towards the sustainable corporation: Win-win-win business strategies for sustainable development. Calif. Manage. Rev. 36, 90-100. 
Fane, S. \& Turner, A. 2009 Integrated Water Source Planning in the Context of Climate Uncertainty. Efficient 2009. International Water Association, Sydney, Australia.

Miller, G.A. 1956 Some limits on our capacity for processing information. Psychol. Rev. 63, 81-97.

Moreno-Pérez, O.M. \& Ortiz-Miranda, D. 2008 Understanding structural adjustment in Spanish arable crop farms: policies, technology and multifunctionality. Span. J. Agric. Res. 6(2), 153-165.

Pekelney, D.M., Chesnutt, T.W. \& Mitchell, D.L. 1996 Cost-Effective Cost-Effectiveness: Quantifying Conservation on the Cheap. American Water Works Association Conference, Toronto, Canada.

Saaty, T. 1980 The Analytic Hierarchy Process: Planning, Priority Setting, Resource Allocation. RWS Publications, Pittsburgh, PA.

Seattle Public Utilities 1998 Water Conservation Potential Assessment. Final Project Report.

WCED (World Commission on Environment and Development) 1987 Our Common Future. Oxford University Press, Oxford, UK.

First received 23 March 2011; accepted in revised form 17 June 2011 